\title{
Enterococcus faecium SF68 as a model for efficacy and safety evaluation of pharmaceutical probiotics
}

\author{
W. Holzapfel ${ }^{1 *}$, A. Arini ${ }^{2}$, M. Aeschbacher ${ }^{2}$, R. Coppolecchia ${ }^{2}$ and B. Pot $^{3}$ \\ ${ }^{1}$ Handong Global University, 3 Namsong-ri Heunghae Buk-gu, Pohang Gyungbuk, 791-708, Republic of Korea; ${ }^{2}$ Cerbios- \\ Pharma SA, Via Figino 6, 6917 Barbengo/Lugano, Switzerland; ${ }^{3}$ Research Group of Industrial Microbiology, Fermentation \\ Technology and Downstream Processing (IMDO), Department of Applied Biological Sciences, Vrije Universiteit Brussel \\ (VUB), Pleinlaan 2, 1050 Brussels, Belgium; wilhelm@woodapple.net
}

Received: 14 October 2017 / Accepted: 11 December 2017

(c) 2018 Wageningen Academic Publishers

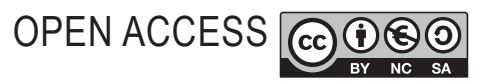

REVIEW ARTICLE

\begin{abstract}
As normal inhabitants of diverse ecosystems, including the human gastrointestinal tract, the enterococci, and especially the two species Enterococcus faecalis and Enterococcus faecium, can be considered ubiquitous with regard to our natural environment. E. faecium has gained special importance thanks to beneficial strains marketed as probiotics, and because of its beneficial role in traditional fermented foods such as artisanal cheeses in some Southern European countries. Yet, following reports on the increasing association of some enterococcal strains with nosocomial infections such as endocarditis and bacteraemia, it became evident that strains from clinical origin are frequently highly resistant to 'last-defence-line' antibiotics such as the glycopeptide derivatives. For this reason enterococci have been classified in risk group 2 in the European Directive 93/88. With this paper it is intended to clarify the uncertain situation around the safety of the species E. faecium, also with referring to intra-species heterogeneity. In fact, well established scientific and surveillance data support the safety of some probiotic E. faecium strains for both human and animal applications. As a model, summarising yet extensive information is provided on the efficacy and safety of $E$. faecium $\mathrm{SF} 68^{\circ}$, a pharmaceutical probiotic with a long history of safe use. We propose the approach presented in this review as a model for the evaluation of safety of probiotic strains of this species.
\end{abstract}

Keywords: probiotic, Enterococcus faecium SF68, safety, pharmaceutical probiotics

\section{Introduction}

Use of probiotics is widely recognised as a promising approach for stabilising or improving the intestinal system (Holzapfel et al., 1998). Unlike probiotics commercialised as 'health-food', pharmaceutical probiotics require the preparation of a pharmaceutical registration file and an approval by the health authority of the respective country. The requirements for such a registration may vary from country to country but basically, besides the technical part of the dossier (manufacturing, quality and stability), a complete documentation regarding efficacy and safety is required. Most of the pharmaceutical probiotics available today have been registered in the 70's and 80's following national regulation. The dossiers are regularly updated as required by the health authorities, in particular with regard to safety. Typically, the respective data are supplied exclusively to the health authorities and are not available in the public domain in a comprehensive form. So far no pharmaceutical probiotic has followed a central registration allowing for EU wide commercialisation. In fact, the pharmaceutical regulations in the EU were designed for chemical molecules and are thus not adapted to pharmaceutical probiotics containing live microorganisms as active ingredients. As a consequence, the European Medicines Agency (EMA; http://www.ema.europa.eu/ema) has currently no ready to use protocol to evaluate dossiers with live microorganisms. The Pharmabiotic Research Institute is a European non-profit organisation that is currently in contact with the pharmaceutical authorities in order to establish such a validated European procedure (http://www.pharmabiotic.org/about-pri). In the meantime, 
dossiers can be submitted on the national levels, but there is no standardisation of the required format or evaluation procedure.

Enterococci are components of the normal microbiological population of the human gastrointestinal tract (GIT). They are ubiquitous and may be found in various ecosystems, ranging from soil, surface waters, waste and municipal (treated) waters, plants, the gastrointestinal tract of warm-blooded animals and humans, as well as in foods. The species Enterococcus faecalis, Enterococcus faecium, Enterococcus durans and Enterococcus hirae appear to be typically associated with the human gastrointestinal tract; their presence in/on food may thus indicate faecal origin (Švec and Franz, 2014). In many food products they are naturally present (Carrer Gomes et al., 2010; Devriese and Pot, 1995), while they may also typically be associated with some traditional fermentations, or are deliberately added as starter cultures (Battistotti, 1976, 1977; Bourdichon et al., 2011; Burgos and Ordonez, 1977; FAIR, 2000; Franz et al., 2003; Gallman and Puhan, 1982; Jensen, 1975).

E. faecium $\mathrm{SF}^{\circ} 8^{\circ}$ (SF68) has been used as a probiotic, both in pharmaceutical and animal nutrition applications. It is approved as a pharmaceutical probiotic by the health authorities of different countries, starting from Switzerland in 1979 and, under the name of E. faecium NCIMB 10415, SF68 is approved by EFSA as a 'gut flora stabiliser' for various animal categories (http://tinyurl.com/ycbyu35p). The purpose of this review is to provide an overview of the efficacy and safety of pharmaceutical probiotics containing Enterococcus faecium as the active ingredient, with special reference to SF68.

\section{Efficacy of SF68 for the treatment of intestinal disorders in humans}

The original SF68 strain was isolated in 1968 from the faeces of a healthy breast-fed new-born baby and deposited as E. faecium NCIMB 10415 (Asplund, 1991). The strain belongs to a pioneer type of bacteria, i.e. the first lactic acid bacteria transmitted from the mother's milk to the newborn, allowing for the development of a healthy microbiome in the gastrointestinal tract (Martín et al., 2003; Wopereis et al., 2014).

The efficacy of SF68 has been tested in more than 20 placebo-controlled clinical trials, 13 of them having a double-blind trial setting (Table 1). Overviews on the biological properties of SF68 and its clinical application have been published by Lewenstein et al. (1979) and Loizeau (1994). SF68 is used in the clinic, amongst others, for the normalisation of the intestinal microbiota in case of gastrointestinal disorders of adults, children and infants, and for the treatment of acute diarrhoea resulting from gastro-enteritis, enteritis or enterocolitis (AD).
Four double-blind clinical trials, sharing the same primary endpoint and representing 333 patients, were included in a Cochrane review on 'probiotics for treating acute infectious diarrhoea' (Allen et al., 2010). According to the overall performance reported therein, treatment with SF68 significantly reduced the risk of suffering from diarrhoea after four days of treatment with a relative risk (RR 95\%) ranking at $0.210(P=0.0001)$ and a confidence interval of 0.08-0.52. Another important application of SF68 is the prevention and treatment of antibiotic associated diarrhoea (AAD). The respective clinical trials are reported in Table 1 as well as in D'Souza et al. (2002).

In addition, efficacy of SF68 was evaluated in other clinical applications, such as hepatic encephalopathy and irritable bowel syndrome (Table 1). So far, only 2 clinical studies performed with pharmaceutical products containing SF68 did not show efficacy: a double blind clinical trial on watery diarrhoea in 183 Bangladeshi adults (Mitra and Rabbani, 1990), and another, open, comparative study, on acute diarrhoea in children (Canani et al., 2007). The Mitra and Rabbani study was excluded from the above mentioned Cochrane review (Allen et al., 2010) due to the lack of a true placebo group. In none of the clinical trials adverse events linked to SF68 were reported; this finding is in line with the safety data reported here.

\section{Safety of SF68}

Due to the fact that drug regulatory documentation is not generally available in the public domain, the safety of SF68 as a pharmaceutical probiotic has sometimes been questioned, based on fears at level of the species (Elmer, 2001). However, safety assessments need to be conducted at strain level and not at species level (Bernardeau et al., 2008; Laulund et al., 2017; Sanders et al., 2010).

In the meantime, however, some publications have reported the safety of SF68 (Franz et al., 2009, 2011; Kayser, 2003). The aim with the safety data reported here is to provide additional insight into the large amount of scientific information available on SF68, including unpublished results that are part of the pharmaceutical registration file approved by health authorities where the product is commercialised. The approach presented here is an illustration of a diversity of safety report elements that can be considered when a safety dossier for a probiotic strain is to be prepared.

\section{In vivo safety assessment}

Preclinical studies with SF68 have been performed following protocols traditionally used for pharmaceutical drug master files (Unpublished data from F. Bistoni, 1982, CerbiosPharma registration file, E. Marmo, 1978; F. Negretti, 1991). Results are briefly summarized below. These data 


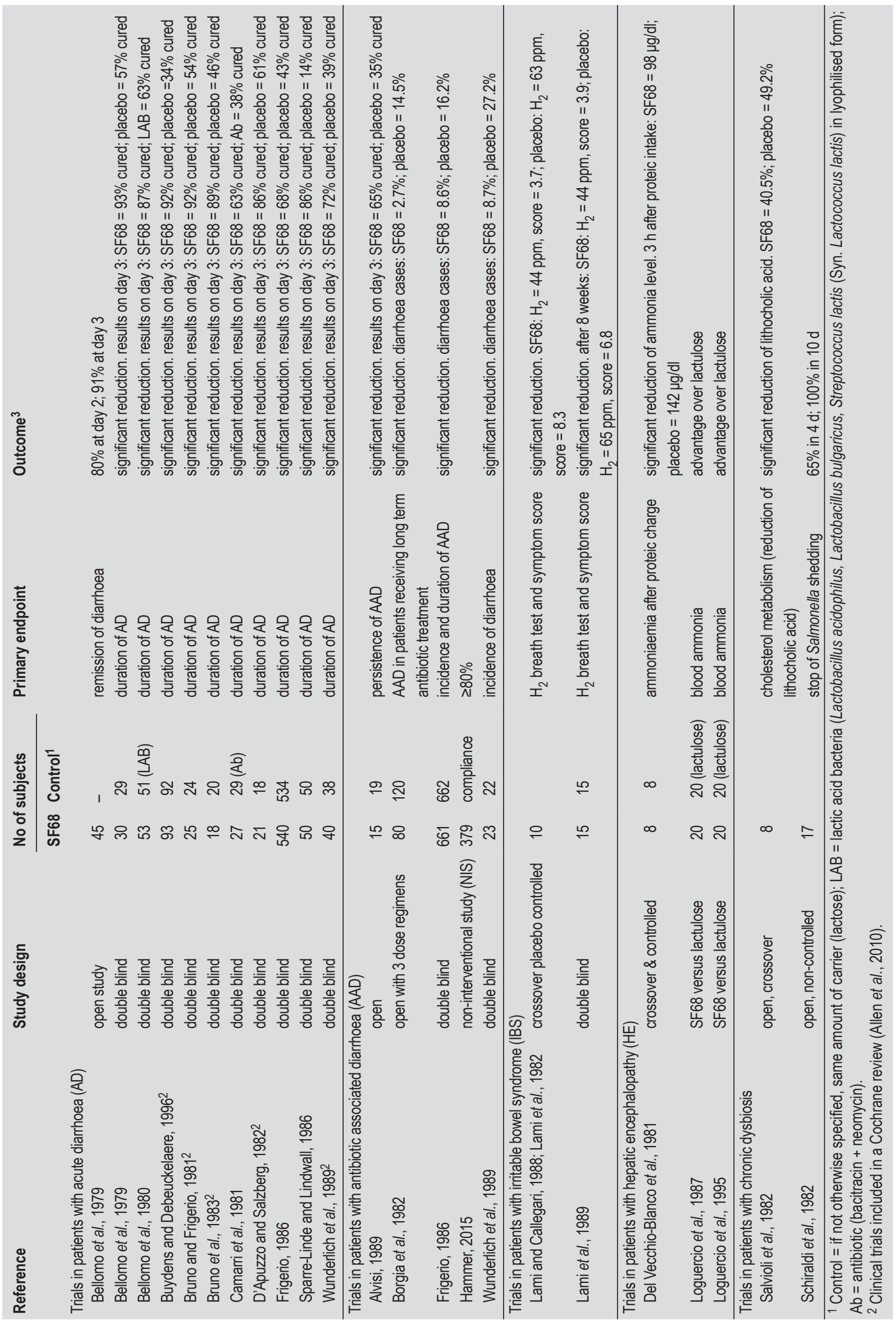


are normalised towards a daily human (body weight of $75 \mathrm{~kg}$ ) therapeutic dose (DTD) of 3 capsules/day with a content of 75 million cfu SF68/capsule.

Acute toxicity effects were tested in adult albino rats and mice. Ten animals of each group (respectively 5 males and 5 females per group) were fasting for $12 \mathrm{~h}$ before the treatment, with water ad libitum. Seven days after a single administration of SF68 by gavage, no visible toxic symptoms appeared. In terms of cfu $/ \mathrm{kg}$ body weight, dosages of up to a 600 -fold the DTD recommended for humans, gave neither immediate nor delayed disorders and even a 2,400fold DTD had no lethal effect; only moderate behavioural changes were recorded. After intraperitoneal administration of a 1,200-fold DTD, toxic-lethal effects were noted with a mortality of 10-20\%. In another mice study no lethality was induced by oral administration of a 500,000-fold human DTD, normalised according to body weight. The LD50 after 10 days for an intraperitoneal administration, was set at $>140,000$ times the DTD, corresponding to 100 times the LD50 value for Salmonella Typhimurium.

Translocation of SF68 from the gastrointestinal tract to other organs has never been reported. Even intravenous injection in immune depressed mice of more than 13,000fold the DTD of SF68 was not lethal, and no traces (cfu) of the strain could be detected in the liver, kidney and heart after two weeks of administration. This is in line with the observations that SF68 has an extremely low ability to adhere to the intestinal epithelial cells, which is the first step for invasion (see 'Adhesion to epithelial cells' below). In addition, recent in vitro experiments performed on porcine jejunal epithelial cells (IPEC-J2) challenged with enterotoxigenic Escherichia coli (ETEC) have shown that SF68 is able to prevent cell death and to preserve the physiological epithelial cell structure (Kern et al., 2017).

The sub-acute toxicity was studied in 30 rabbits, which were divided into 3 groups of 5 male and 5 female animals each, for a period of 30 days. The powder form was administered daily by gavage to two groups, at a 10 -fold and 30 -fold DTD, respectively. The third group remained untreated and served as the control group. The treated animals were in excellent condition during the whole period. No toxic symptoms were ascertained and no lethal events occurred. The animals were sacrificed $24 \mathrm{~h}$ after the last administration. The study of physiological parameters [blood glucose, blood urea nitrogen (BUN), peripheral blood test] and the histological examination of various organs (liver, kidney, adrenal glands, heart, lungs, spleen, pituitary gland) showed no significant impairments.

Chronic toxicity tests were carried out on young rats and adult dogs. For 180 consecutive days 3 groups of 10 rats (5 males and 5 females each) received, respectively, 0, 5 or 20 times the DTD by gavage. The rats maintained in an excellent general health state. Neither lethal events nor toxic symptoms were observed. $24 \mathrm{~h}$ after the last administration, the following parameters were measured: BUN, blood glucose levels, peripheral blood test (red and white blood cell counts), serum-glutamate-oxalaocetatetransaminase and serum-glutamate-pyruvate-transaminase. A renal function test was also performed. After sacrifice, the most important organs (liver, heart, kidney, adrenal glands, testes, ovaries, thyroid gland, hypothalamus, lungs, and spleen) were studied. No significant variations were found in both the functional parameters and the histological structure of the organs tested. Similar oral studies were performed in 6 adult dogs ( 3 female and 3 male animals), leading to the same results.

Embryotoxic trials were carried out on 30 rats and 30 rabbits, divided into 3 groups each, with 10 animals of each being used as controls. From the third day of pregnancy, for 15 consecutive days, the animals received either a 5 -fold or 20-fold DTD orally. All rats and rabbits were sacrificed either on the $20^{\text {th }}$ or on the $29^{\text {th }}$ day and their uteri were examined in detail. Similar examinations were carried out on the foetuses, including the analysis of their weight and, for some, on possible skeletal deformations. Results showed that the administration of the product did not bring about relevant changes to the mother animals during their pregnancy, nor produced skeletal malformations or weight loss in the foetuses.

Local tissue tolerance was tested by single or repeated oral administrations in rats and dogs. The dogs received orally a 5 -fold or 20-fold DTD, respectively, for 180 days. The rats received the powder for 120 days by gavage. The daily dosages were also either 5-fold or 20-fold the DTD. Animals were sacrificed 24 to $28 \mathrm{~h}$ after the last application and areas of gastric and intestinal mucous membranes were examined histologically. No variations were found in the mucosal membranes of the stomach or the intestine, even after repeated application of the product.

Besides its application as a pharmaceutical product, SF68 has been used in animal nutrition, benefiting from national registrations since the 1970s and an approval as feed additive in the EU since 1999 (http://tinyurl.com/y9d8bphk). In the EU SF68 was registered as E. faecium NCIMB 10415, following the Directive 70/524/EEC (EC, 1993) and was later submitted for re-evaluation under the Regulation (EC) No. 1831/2003 (EC, 2003) with the trademarks Cylactin and Cernivet. EFSA has conducted several safety assessments of the strain and their opinions are publicly available. Briefly, besides genetic and phenotypic analysis, various tolerance tests were performed in different animal species, with up to 100 times the recommended daily dose. In none of these experiments negative events were reported. Therefore, EFSA has considered probiotic feed additives with E. faecium strain NCIMB 10415 as 'safe' and granted 
regulatory approval for a number of animal species and categories (EFSA, 2010, 2013a,b, 2014, 2015).

\section{Long history of safe use in humans}

SF68 can be considered as one of the best characterised probiotics with respect to safety, and has an exceptionally long history of safe use in probiotic therapy, going back to its early use as pharmaceutical preparation in 1979. Since then and up to the end of 2015 about 1.5 billion single doses (capsules) of SF68 have been commercially distributed (IMS Health Dataview and Cerbios-Pharma sales statistics). Assuming an average daily dosage of 3 capsules and a treatment of 7 days, more than 70 million patients have been treated with pharmaceutical probiotics based on SF68. As reported in the periodic safety update reports (PSUR), no adverse drug reactions (ADR) were reported since 1979, neither from health care professionals or regulatory authorities, nor from other sources concerned with safety and efficacy (Cerbios Pharma, producer of the SF68). Infections with or without lethal outcome have never been reported for SF68 during all these years and despite its broad application in a monitored clinical context.

\section{Antibiotic resistance profile of SF68}

Generally speaking, most, if not all, microorganisms exhibit different levels of resistance against one or more antimicrobial agents. Some of the resistances have been defined as 'intrinsic' in the case they would have been developed along the speciation of the microorganism, or 'acquired', in the case they would have been acquired by horizontal gene transfer from other microorganisms. The increased use of antibiotics resulted in selective pressure on microorganisms, favouring those with multiple resistances. This, of course, is a reason of concern for human and animal health, especially in case the recipient strain is a pathogenic microbe.

The antibiotic resistance pattern of SF68 does not differ from the typical natural and intrinsic resistance profiles generally found in non-pathogenic E. faecium (Table 2). These data have been confirmed by several laboratories,

Table 2. Summary of the antibiotic resistances in SF68.

\begin{tabular}{|c|c|c|c|c|c|c|}
\hline \multirow[t]{2}{*}{ Antibiotic group } & \multirow[t]{2}{*}{ Antibiotic } & \multirow[t]{2}{*}{ Susceptibility } & \multicolumn{3}{|c|}{ Genetic status of resistance } & \multirow{2}{*}{$\begin{array}{l}\text { Reference method for } \\
\text { minimum inhibitory } \\
\text { concentration }\end{array}$} \\
\hline & & & Searched genes & Intrinsic & $\begin{array}{l}\text { Acquisition or } \\
\text { transmissibility }\end{array}$ & \\
\hline Penicillins & ampicillin ${ }^{1}$ & sensitive & & - & - & $\begin{array}{l}\text { CLSI }^{2} \\
\text { NCCLS M7-A3 }\end{array}$ \\
\hline Glycopeptides & vancomycin & sensitive & absence of van genes & - & none & $\begin{array}{l}\text { CLSI } \\
\text { NCCLS M7-A3 }\end{array}$ \\
\hline \multirow[t]{3}{*}{ Aminoglyco-sides } & gentamicin & sensitive & & - & - & $\begin{array}{l}\text { CLSI } \\
\text { NCCLS M7-A3 }\end{array}$ \\
\hline & kanamycin & resistant & genetic basis unravelled & intrinsic & none & $\begin{array}{l}\text { CLSI M07-A8 } \\
\text { NCCLS M7-A3 }\end{array}$ \\
\hline & streptomycin & sensitive & & - & - & $\begin{array}{l}\text { CLSI } \\
\text { NCCLS M7-A3 }\end{array}$ \\
\hline Macrolides & $\begin{array}{l}\text { neomycin } \\
\text { erythromycin }\end{array}$ & $\begin{array}{l}\text { sensitive } \\
\text { resistant }\end{array}$ & $\begin{array}{l}\text { absence of ermB gene; } \\
\text { genetic basis unravelled }\end{array}$ & $\begin{array}{l}- \\
\text { intrinsic }\end{array}$ & $\begin{array}{l}- \\
\text { none }\end{array}$ & $\begin{array}{l}\text { agar dilution test } \\
\text { CLSI } \\
\text { NCCLS M7-A3 }\end{array}$ \\
\hline Tetracyclins & tetracycline & sensitive & & - & - & $\begin{array}{l}\text { NCCLS agar diffusion test } \\
\text { CLSI }\end{array}$ \\
\hline Sulfonamids & trimethoprim & sensitive & & - & - & $\begin{array}{l}\text { CLSI } \\
\text { agar dilution test }\end{array}$ \\
\hline \multirow[t]{4}{*}{ Others } & linezolid & sensitive & & - & - & CLSI \\
\hline & quinupristin + dalfopristin & sensitive & & - & - & CLSI \\
\hline & chloramphenicol & sensitive & & - & - & $\begin{array}{l}\text { NCCLS agar diffusion test } \\
\text { CLSI }\end{array}$ \\
\hline & clindamycin & sensitive & & - & - & CLSI \\
\hline
\end{tabular}


as the strain was studied in the frame of EU projects, such as ENTIP (FAIR-CT97-3078), where SF68 is reported as 'E24' as well as in the PROSAFE FWP5-QLRT-2000-01273 project (Franz et al., 2001; Vankerckhoven et al., 2008a). Further studies were carried out aiming at elucidating the genetic determinants at the basis of the observed resistance to erythromycin and kanamycin/tobramycin.

Previous studies with SF68 have been performed following protocols used for pharmaceutical drug master files (unpublished data reviewed by Arini, 2007, 2010, 2011; Cerbios-Pharma registration file; Coppolecchia, 1994, 1997; ENTIP, 2002; EFSA, 2010, 2013; Hernandez, 2010; Kayser 1996; Reuter, 1996; Solioz, 1992). Results are briefly summarised in the following paragraphs.

\section{Ampicillin resistance}

SF68 was found sensitive to ampicillin with a Minimum inhibitory concentration (MIC) below $1 \mathrm{mg} / \mathrm{l}$. In the 'Guidance on the safety assessment of E. faecium in animal nutrition' (EFSA, 2012), the EFSA Panel on Additives and Products or Substances used in Animal Feed, is assessing how to exclude E. faecium strains belonging to hospitalassociated clades (for phylogenetic information on the species, see further below) from the use in animal (and by extension also in human) nutrition because of the hazard they present to a vulnerable subpopulation of consumers. In this document EFSA is proposing ampicillin resistance as a marker for the discrimination between E. faecium strains from human infection as compared to strains of food origin, and they conclude that, due to differences in the consensus low-affinity class B penicillin binding protein 5 (PBP5fm) a MIC $\geq 4 \mathrm{mg} / \mathrm{l}$ can serve to reliably exclude isolates from human clinical origin and thereby avoid the use of strains that might have a selective advantage in the GI tract if an individual was given ampicillin, amoxicillin or similar antibiotics (Galloway-Peña et al., 2011; Rice et al., 2004). However, this clade distinction is not applicable for qualified presumption of safety (QPS) since the QPS approach relies on taxonomic units, where the species/subspecies level is the lowest level of evaluation (EFSA, 2017).

\section{Erythromycin resistance}

Gene disruption was used to show that the presence of the intrinsic gene $m s r C$, as described by Singh et al. (2001), was responsible for the low level resistance of SF68 to erythromycin. Absence of the ermB gene was demonstrated by PCR (EFSA, 2010).

\section{Kanamycin/tobramycin resistance}

The presence of the intrinsic $a a c$ (6')-li gene has also been demonstrated, by gene disruption, to be responsible for SF68's resistance to tobramycin and, in a more moderate extent, to kanamycin. The genetic basis of kanamycin resistance in SF68 was attributed through double gene disruption to the presence of two genomic intrinsic traits, acting synergistically: (1) the $a a c\left(6^{\prime}\right)$-li gene, an acetyl transferase (Costa et al., 1993), and (2) the gene $\mathrm{sfkm}^{r}$, a putative rRNA-methyltransferase, described by Galimand et al. (2011) as efm $M$ and reviewed by Hollenbeck et al. (2012).

Moreover, a bioinformatics search within the SF68 genome confirmed the absence of all the aminoglycoside resistance genes that are described in literature as transmissible (Chow, 2000) and that are defined as 'acquired' in some resistant E. faecium strains (EFSA, 2010).

In terms of capability to promote the transfer of kanamycin or erythromycin resistance genes to recipients of the same species and to other enterococci, SF68 can be considered a very poor donor. In fact the intrinsic resistances to kanamycin and tobramycin as well as the intrinsic lowlevel resistance to erythromycin, could not be transmitted by conjugation from SF68 to other enterococci.

\section{Glycopeptide resistance}

SF68 has not acquired any of the resistance determinants that have been of clinical concern in the last decades, such as glycopeptide or high level macrolide resistances. In fact, SF68 is susceptible to vancomycin and, moreover, low dosage exposure to this antibiotic was shown to fail in inducing resistance. Even under selective pressure, in conjugation tests, SF68 did not acquire the vancomycin (vanA) resistance gene from a vancomycin resistant $E$. faecium strain. Data collected on the level of transmissibility of glycopeptide resistance in other probiotic enterococcal strains ranged between $1.2 \times 10^{-6}$ and $4 \times 10^{-7}$, as compared to $>2 \times 10^{-4}$ for an E. faecium control strain (Klein et al., 1995).

Similar conjugation experiments, carried out with the Klein protocol for conjugation (Klein et al., 1995) and using the same E. faecium control strain as a donor, showed vancomycin resistance transfer rates as low as $7 \times 10^{-8}$ into E. faecium SF68 as recipient, 4 log units lower than with the international control strain E. faecium 64/3 $\left(>2 \times 10^{-4}\right)$.

Interestingly, in a study conducted to determine if SF68 could compete with the vancomycin-resistant strain DSM 13590, SF68 did not acquire any vancomycin resistance but outcompeted the resistant strain, which became undetectable after five days of co-culture (ENTIP, FAIRCT97-3078).

The poor capacity of SF68 to uptake genetic material may be correlated to impairment in the correct assembly of the DNA uptake machinery. In fact, an 'in silico' comparative analysis of some of the peptide sequences involved in the natural competence in E. faecium, carried out by means of 
the FASTA (TFASTX) alignment program, has shown the presence of non-sense and frame-shift mutations in some of the crucial genes encoding for competence (regulation/ acquisition) factors, like comB (GenBank: SEU01945); comC (GenBank: AGE31261.1) and comD (GenBank: AGE29265.1) (Shanker and Federle, 2017).

Finally, it was established in specifically designed experiments with 10 clinically relevant antibiotics that no resistance developed through spontaneous mutation by plating $10^{8}$ cfu of SF68, whereas antibiotic resistant colonies were found by plating the same cfu concentration of $E$. faecalis ATCC 29212 and E. faecium V06-802 resulting in resistant colonies in 1 or 5 out of 10 antibiotics, respectively (unpublished data from EFSA, 2010; Kayser, 2003).

Considering the poor capacity of SF68 to exchange genetic material with strains belonging to the same species, we can state with confidence that the risk of transmission of resistances to other species and genera is negligible.

\section{Safety aspects related to virulence factors}

Prior to the identification of multiple antibiotic resistant strains in the late seventies, enterococci were considered harmless bacteria, with the exception of enterococci causing endocarditis. Over the last two decades increasing nosocomial infections caused by enterococci were found among hospitalised patients. These occurred especially in the intensive care units, when the host conditions are such that they enable bacterial colonisation outside the GIT, causing infections of the urinary tract and sometimes of abdominal wounds. Some nosocomial infections evolved into bacteraemia or endocarditis. Discussion on enterococci, being 'at a crossroad of food safety' (Franz et al., 1999) started to become more frequent. Infections caused by highly resistant strains (Kayser, 2003; Murray, 1990) are considered particularly difficult to overcome. This is the reason why in the European Directive 93/88 (EC, 1993), enterococci are classified in the risk group 2 , with the exception of specific strains known to be non-pathogenic and with a (technical) history of safe use (BAUA, 2015).

Virulence factors present in some of the infecting strains might be the basis of their pathogenicity classification (Eaton and Gasson, 2001). The pathogenic potential of clinical isolates of enterococci has been mainly correlated to the production of aggregation substance and other components favourable for the spreading of the bacteria, such as haemolysin, gelatinase, hyaluronidase, endocarditis antigen EfaAfs/EfaAfm, surface protein Espfm and adhesion protein Ace/Acm-adhesin.

SF68 has been tested for a number of virulence factors. Results are briefly summarised below. (Unpublished data reviewed by Arini, 2000, 2010, 2011, 2012, 2016; Cerbios-
Pharma registration file; Coppolecchia, 1994; EFSA, 2010, 2013; ENTIP, 2002, 2004; FAIR, 2000; François, 2012; Goossens, 2005).

\section{Aggregation substance}

SF68 did not show any aggregation capacity. The absence of asa-type genes (encoding for the aggregation substance) was demonstrated in experiments with PCR-amplification and gene probes specific for $a s a 1$ and asa373. Furthermore, a genomic search confirmed the absence of both the asa1, asa373 and of the more recently described genes encoding for proteins with similar aggregation properties as asp 1 and $\operatorname{asc} 10$.

\section{Haemolysis}

Blood agar colony phenotyping of SF68 showed that this strain does not produce $\beta$-haemolysis. The absence of $\mathrm{O}$-streptolysin of streptococci and of cytolysin genes (cylA, $c y l B, c y l L(L), c y l M$ and $c y l L(S)$, involved in production and maturation of cytolysin was demonstrated by PCR and by bioinformatics search on the SF68 genome (Carbone et al., 1980; Franz et al., 2001).

\section{Gelatinase}

No evidence of gelatine lysis on agar containing gelatine or skim milk was observed. The search for corresponding gelatinase gene ( $g e l E$ ) gave negative results. The genes $f s r A$, $f_{s r} B, f_{s r} C$ and $f_{s r} B / D$ active in the regulation of the gelE expression were also found to be absent in SF68 in PCR experiments, as well as in a bioinformatic search on the SF68 genome. Similar to gelatinase, the SprE proteinase was more recently described in some $E$. faecium strains as responsible for an increased mortality in animal infection models. The bioinformatics search of the sprE gene in SF68 was also negative.

\section{Hyaluronidase}

K-hyaluronate, contained in a suitable agar medium (Balke and Weiss, 1984), was not degraded, confirming that hyaluronidase is not produced by SF68. The absence of the gene was further demonstrated by bioinformatics search within the SF68 genome sequence and by PCR.

\section{Endocarditis antigen}

The endocarditis antigen $\left(e f a A_{f m}\right)$ gene could be identified within the SF68 genome both by PCR amplification, as well as through a bioinformatics search on the genome sequence. The assumption that $E f a A_{f m}$ (from $E$. faecium) could harbour some adhesion properties to animal tissues is based exclusively on its $73 \%$ similarity with the EfaA virulence protein of $E$. faecalis and on the ability of the 
latter to be more virulent in a mouse peritonitis model as compared to its disrupted mutant. Therefore, the relevance of this finding is doubtful, as no correlation has been reported between the presence of $e f a A_{f m}$ gene and increased virulence (Singh et al., 1998).

\section{Adhesion to epithelial cells}

The genes Ace (E. faecalis collagen-adhesin gene) and the potential virulence factor Esp(fm) (Enterococcus surface protein, specifically linked to nosocomial clonal lineages) were shown to be absent in the SF68 genome by bioinformatic analysis, confirming earlier PCR specific amplification assays.

The bioinformatics search for acm (gene coding for adhesion to collagen) revealed the presence of a nonfunctional relic of the $\mathrm{acm}$ gene, which underwent a series of rearrangements, encompassing insertion as well as duplication of DNA fragments and the introduction of several non-sense mutations at the 5 '-end of the gene.

These findings are in line with the observation that SF68 has an extremely low ability to adhere to the intestinal epithelial cells, as no adhesion was observed to a variety of surfaces, such as vascular and cardiac valves (Bongetta $e t$ al., 1981; Chisari et al., 1989, 1992; Underdahl et al., 1982).

\section{Colonisation}

SF68 does not colonise permanently, neither in humans nor in animals. After administration a temporary colonisation occurs and the number of SF68 cfu decreases as a function of time from being the predominant enterococcus until becoming undetectable after 9-11 weeks (Vankerckhoven et al., 2005).

\section{Genotyping and phylogeny}

As shown in Figures 1 and 2, SF68 is genetically clearly distinct from enterococcal strains of clinical origin, which generally are multidrug resistant and in many cases were derived from clonal outbreaks. The presence of the mobile element IS16 has been raised as a predictive marker, suitable for the identification of hospital-associated strains (Werner et al., 2011). The absence of the mobile element IS16 from SF68 was first demonstrated by PCR and later confirmed by a bioinformatic search on the SF68 genome (Unpublished data, reviewed by Arini, 2012; Cerbios-Pharma registration file; EFSA, 2013; François, 2012).

\section{AFLP and RAPD analysis}

Using a diverse set of typing technologies, SF68 always grouped together with E. faecium strains of food origin (amplification fragment length polymorphism (AFLP): Sellmaier, 2007; AFLP and random amplified polymorphic DNA (RAPD): Vancanneyt et al., 2002), as is shown in Figures 1 and 2.

\section{e-BURST analysis by MLST}

Another genotypic typing method often used is MLST profiling (multilocus sequence typing, based on 7 gene sequences and their allelic variants). Using the international MLST database (https://pubmlst.org/efaecium), the allelic MLST profile of SF68 was found to be sequence type ST296, frequently found in the 70's in ampicillin and vancomycin sensitive E. faecium isolates that never gave rise to any clinically relevant observation. Interestingly, within the e-BURST diagram obtained for a very large number of E. faecium strains in the MLST database, the sequence type ST296 is quite remote from the hospital associated geno-groups (A and B), which are generally considered to constitute a safety concern (Figure 3) (unpublished data reviewed by Arini et al., 2012; Cerbios-Pharma registration file; EFSA, 2013).

\section{Conclusions}

Based on numerous molecular epidemiological analyses, the species E. faecium appears to be heterogeneous and contains at least two major groups, being distinct in terms of origin, safety characteristics, antibiotic resistance as well as virulence, and, consequently, their ability to produce clinical outbreaks (EFSA, 2017; Vancanneyt et al., 2002; Vankerckhoven et al., 2008b).

This body of knowledge on heterogeneity of the species E. faecium could even be the basis for a formal taxonomic separation of the subgroups, thus enabling the formal definition of a QPS subgroup as already suggested by EFSA (EFSA, 2016). This could avoid confusion in the literature when, e.g. discussing the safe use of probiotic preparations based on E. faecium strains. As required by EFSA, the use of live microorganisms, even if belonging to a taxonomic unit with QPS status, is still subject to some safety evaluations at the strain level. This review provides an overview on the efficacy and safety of SF68, a pharmaceutical probiotic with a long history of safe use. We propose the approach presented above as a model for the evaluation of safety at the strain level, going beyond QPS. Of course, in a pharmaceutical dossier, safety and efficacy data must be accompanied by a robust technical part dealing with manufacturing, handling, control and stability of the probiotic product. 


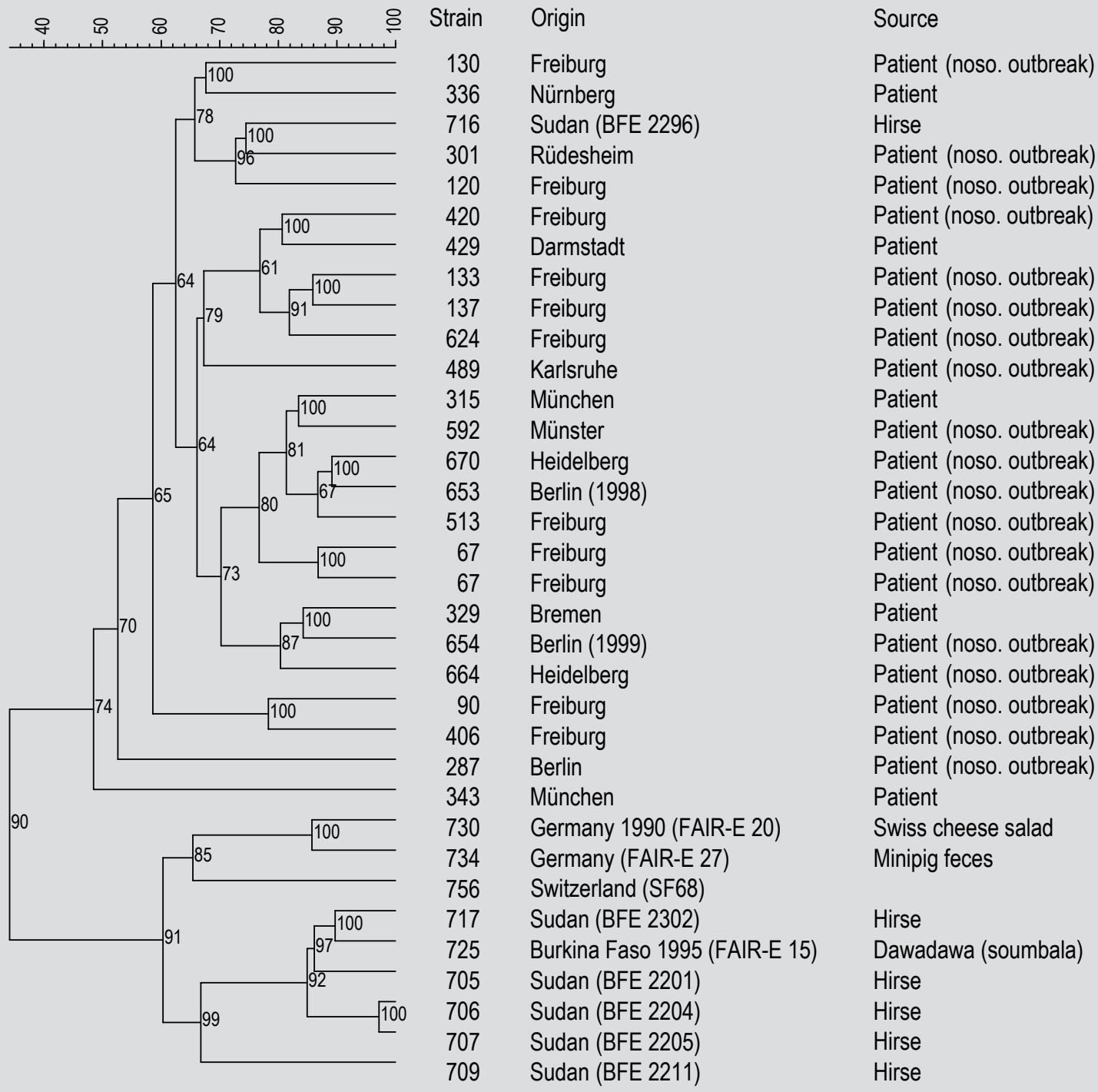

Figure 1. Comparative AFLP-banding pattern of Enterococcus faecium strains from clinical origin compared to those isolated from food plus SF68 clustering into a different group. Adapted and modified from Sellmaier (2007). Hirse = millet. 


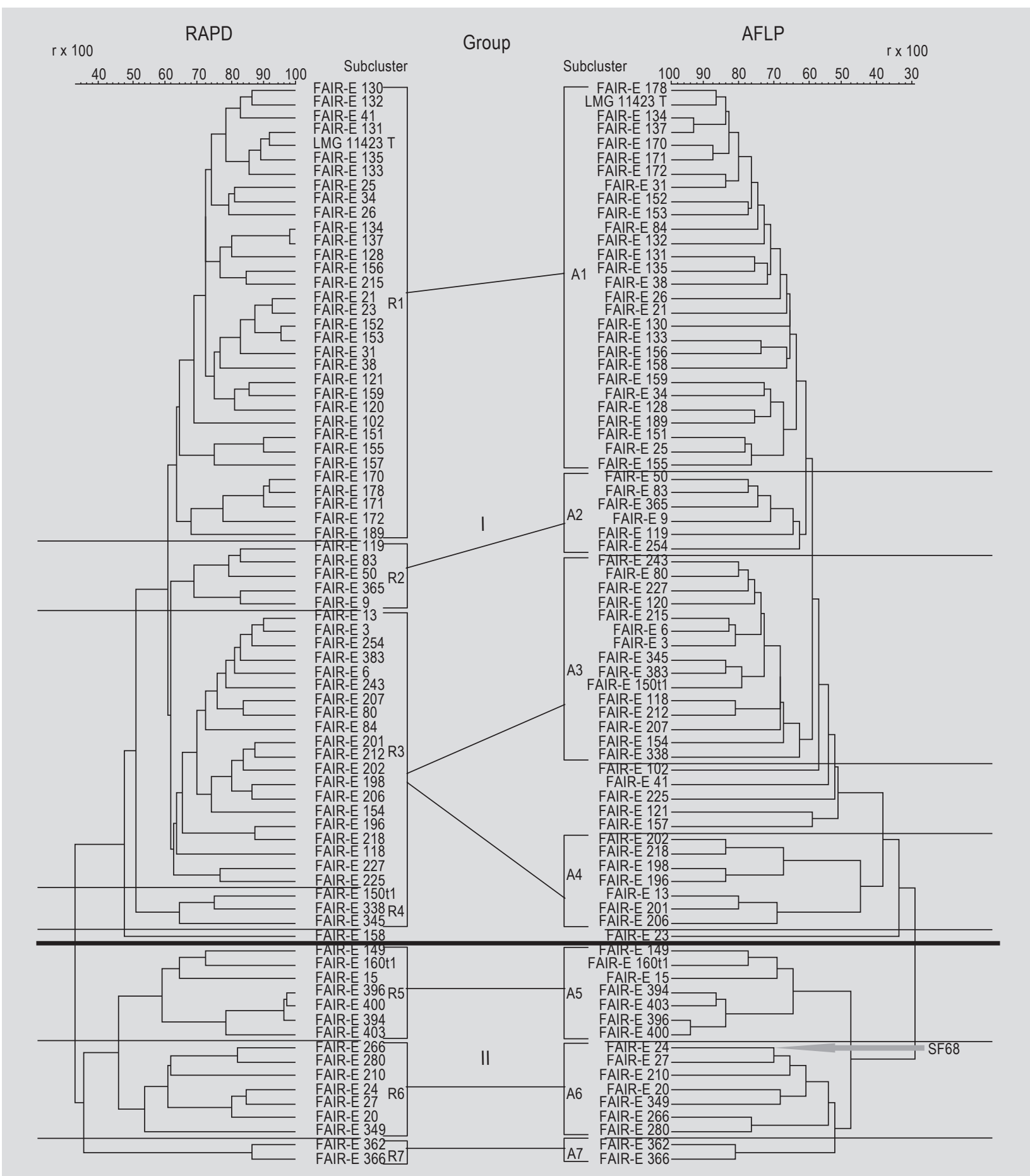

Figure 2. Adapted from Vancanneyt et al. (2002) disclosing SF68, which is in the original figure indicated as FAIR-E 24. Two main genomic groups (I and II) were obtained in both RAPD-PCR and AFLP analyses. Only group I contained strains originating from human clinical samples or strains that were vancomycin-resistant or beta-haemolytic. The two groups could be further subdivided into, respectively, four and three subclusters in both RAPD-PCR and AFLP analyses, and a high correlation was seen between the subclusters generated by these two methods. Subclusters of group I were to some extent correlated with origin/pathogenicity. SF68 was found to belong to group II. 


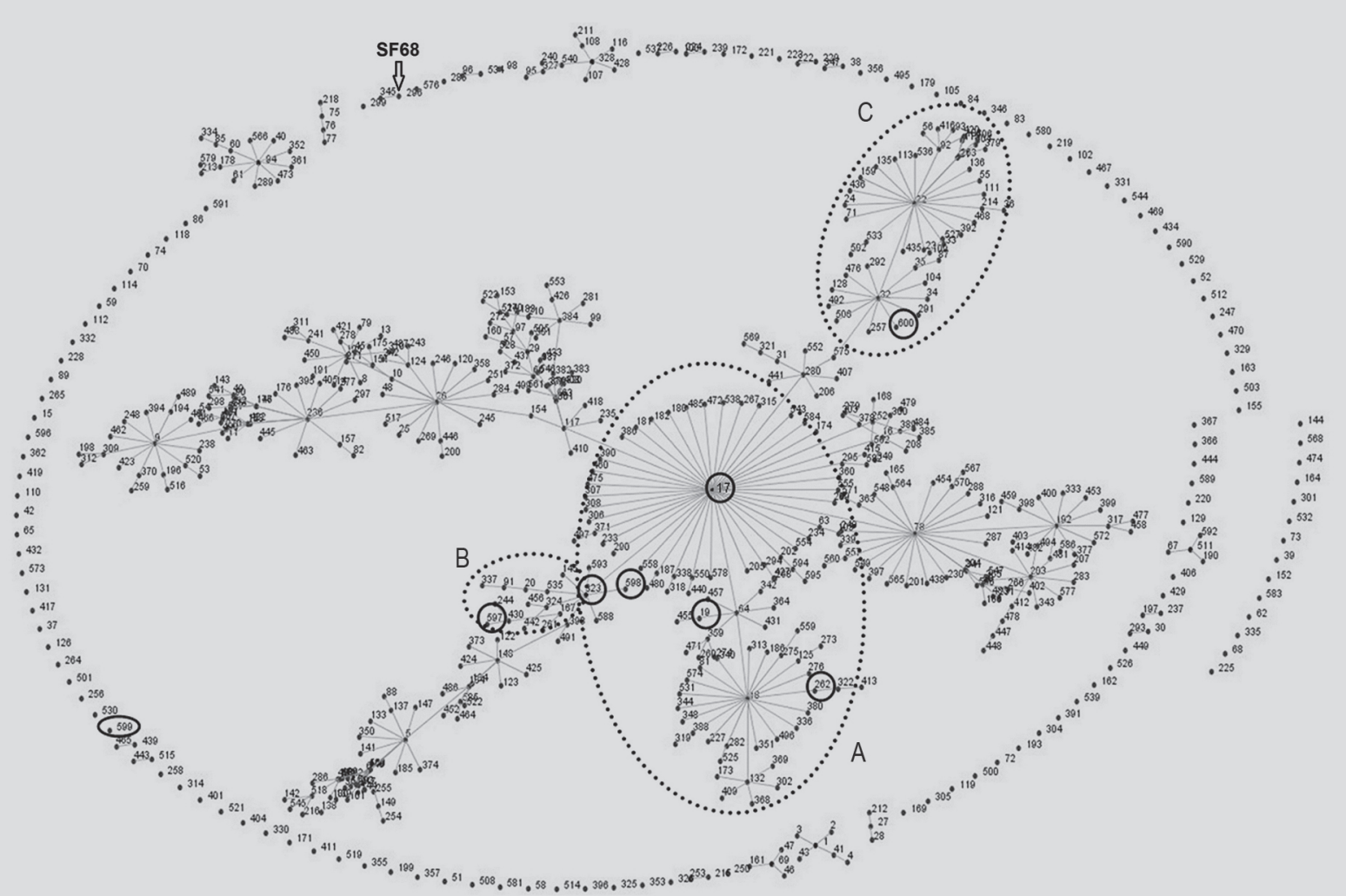

Figure 3. Multilocus sequence typing (MLST), adapted from Ghosh et al. (2011). eBurst clustering of Enterococcus faecium strains (STs). Dotted line circles represent STs from clinical hospital outbreaks (A \& B), or hospital and community surveys, environment and animals (C). SF68, inserted in the analysis using the instructions of Ghosh (2011), remains isolated as a singleton, representing ST296, positioned distantly from clinically relevant isolates.

\section{Conflict of interest}

A. Arini, R. Coppolecchia and M. Aeschbacher are employees of Cerbios-Pharma.

\section{References}

Allen, S.J.B., Martinez, E.G. Gregorio, G.V. and Dans, L.F., 2010. Probiotics for treating acute infectious diarrhoea. Cochrane Database of Systematic Reviews 11: CD003048.

Alvisi, V., 1989. Antibioticoterapia-diarrea e disvitaminosi. Interviste d'attualità Opinioni per il mondo medico. Le Schede di Interviste D’attualita': Opinioni per il Mondo Medico, Suppl. 3/89.

Asplund, A., 1991. Searching the source of life and vitality: the story of my life. Sanomin, Formosan Magazine Press, Ltd., Taiwan, ROC, pp. 72-80.

Balke, E. and Weiss, R., 1984. Einfache Methode zum schnellen Nachweis bakterieller Hyaluronidase in K-Hyaluronat-haltigem Gel. Zentralblatt für Bakteriologie und Hygiene A 257: 317-322.

Battistotti, B., Bottazzi, V. and Vola, G., 1976. Ricerche sulle Caratteristiche Microbiologiche e Chimiche del Formaggio Fontina. Scienza e Tecnica Lattiero-casearia 27: 29.
Battistotti, B., Bottazzi, V. and Vola, G., 1977. Impiego di Str. faecium, Str. thermophilus e Bacilli Lattici nella Caseificazione del Formaggio Fontina. Scienza e Tecnica Lattiero-casearia 28: 331.

Bellomo, G., Finocchiaro, C. and Frigerio G., 1979. Une nouvelle approche pour le traitement des entérites en pédiatrie. Médecine et Hygiène 37: 3781-3784.

Bellomo, G., Mangiagli A., Nicastro L. and Frigerio G., 1980. A controlled double-blind study of SF68 strain as a new biological preparation for the treatment of diarrhoea in pediatrics. Current Therapeutic Research 28: 927-936.

Bernardeau, M., Vernoux, J.P., Henri-Dubernet, S. and Guéguen, M., 2008. Safety assessment of dairy microorganisms: the Lactobacillus genus. International Journal of Food Microbiology 126: 278-285.

Bongetta, R., Quirino, T., Ortisi, G., Privitera, G., Foschi, D., Cavagna, G., Moroni, M. and Rovati, V., 1981. The colonization of Streptococcus faecium in human intestinal tract after oral administration. Bollettino dell'Istituto Sieroterapico Milanese 59: 591-598.

Borgia, M., Sepe, N., Brancato V., and Borgia R., 1982. A controlled clinical study on Streptococcus faecium preparation for the prevention of side reactions during long-term antibiotic treatments. Current Therapeutic Research 31: 265-271. 
Bourdichon, F., Casaregola, S., Farrokh, C., Frisvad, J.C., Gerds, M.L., Hammes, W.P., Harnett, J., Huys, G., Laulund, S. and Ouwehand, A., 2011. Food fermentations: microorganisms with technological beneficial use. International Journal of Food Microbiology 154: 87-97.

Bruno, F. and Frigerio, G., 1981. Eine neuartige Möglichkeit zur Behandlung der Enteritis - Kontrollierte Doppelblindversuche mit dem Stamm SF68. Schweizerische Rundschau für Medizin Praxis 39: 1717-1720.

Bruno, F., Nastasi, A. and Bruno, M., 1983. Studio controllato doppio cieco sull'effetto dell'enterococco lattoproduttore ceppo SF68 su manifestazioni associate a forme enterocolitiche varie e a salmonellosi. Clinica Terapeutica 105: 203-207.

Bundesanstalt fur Arbeitsschutz und Arbeitsmedizin (BAUA), 2015. TRBA 466. Einstufung von Prokaryonten (Bacteria und Archaea) in Risikogruppen. Gemeinsames Ministerialblatt 46-50: 910.

Burgos, J. and Ordónez, J.A., 1977. Etude de la variete de fromage 'Ulloa': preparation d'un levain pour sa fabrication a partir de lait pasteurise. Le Lait 565-566: 278-286.

Buydens, P. and Debeuckelaere, S., 1996. Efficacy of SF68 in the Treatment of Acute Diarrhea. A Placebo-Controlled Trial. Scandinavian Journal of Gastroenterology 31: 887-891.

Camarri, E., Belvisi, A., Guidoni, G., Marini, G. and Frigerio, G., 1981. A double-blind comparison of two different treatments for acute enteritis in adults. Chemotherapy 27: 466-470.

Canani, R.B., Cirillo, P., Terrin, G. Cesarano, L., Spagnuolo, M.I., De Vincenzo, A., Albano, F., Passariello, A., De Marco, G., Manguso, F. and Guarino, A., 2007. Probiotics for treatment of acute diarrhoeia in children: randomized clinical trial of five different preparations. British Medical Journal 335: 340.

Carbone, M., Bobnina, L. and Fera, M.T., 1980. Microbiological properties of Streptococcus faecium SF68 strain and its relationships with other microorganisms. Bollettino dell'Istituto Sieroterapico Milanese 59: 591-598.

Carrer Gomes, B., Gombossi de Melo Franco, B. and Pereira de Martinis, E.C., 2010. Dualistic aspects of Enterococcus spp. in foods. In: Méndez-Vilas, A. (ed.) Current research, technology and education topics in applied microbiology and microbial biotechnology. Formatex Research Center, Badajoz, Spain, pp. 1119-1125.

Chisari, G., LoBue, A.M., Drago, L., Abbiati, R., Castiglioni, G. and Gismondo, M.R., 1989. Ruolo dell'Enterococcus faecium SF68 nell'infezione sperimentale del topo. Giornale Italiano di Chemioterapia 36: 65-68.

Chisari, G., LoBue, A.M., Drago, L., Abbiati, R., Castiglioni, G. and Gismondo, M.R., 1992. Adherence ability of Enterococcus faecium (SF68) and Enterococcus faecalis on various substrates (English translation). Giornale Italiano di Chemioterapia 39: 11-15.

Chow, J.W., 2000. Aminoglycoside resistance in Enterococci. Clinical Infectious Disease 31: 586-589.

Costa, Y., Galimand, M., Leclercq, R., Duval, J. and Courvalin, E. 1993. Characterization of the chromosomal aac (6')-li gene specific for Enterococcus faecium. Antimicrobial Agents and Chemotherapy 37: 1896-1903.
D’Souza, A.L., Rajkumar, C., Cooke, J. and Bulpitt, C.J., 2002. Probiotics in prevention of antibiotic associated diarrhoea: metaanalysis. British Medical Journal 324: 1361.

D’Apuzzo, V. and Salzberg, R., 1982. Die Behandlung der akuten Diarrhö in der Pädiatrie mit Streptococcus faecium: Resultate einer Doppelblindstudie. Therapeutische Umschau 39: 1033-1035.

Del Vecchio-Blanco, C., Ambrogio G., Mattera D., and Coltorti M., 1981. Influence du traitement par Streptococcus faecium (SF68) sur la courbe ammoniémique de charge protéique chez des sujets atteints de cirrhose hépatique. Médecine et Hygiène 39: 2387-2389.

Devriese, L.A. and Pot, B., 1995. The genus Enterococcus. In: Wood, B.J.B. and Holzapfel, W.H. (ed.) The genera of lactic acid bacteria. Blackie Academic \& Professional, London, UK, pp. 327-367.

Eaton, T.J. and Gasson, M.J., 2001. Molecular screening of Enterococcus virulence determinants and potential for genetic exchange between food and medical isolates. Applied and Environmental Microbiology 67: 1628-1635.

Elmer, G.W., 2001. Probiotics: 'living drugs'. American Journal of Health-System Pharmacy 58: 1101-1109.

EU Shared Cost Project FAIR - CT97 - 3078 (FAIR), 2000. Enterococci in food fermentation: functional and safety aspects. Available at: https://tinyurl.com/yc8el4wc.

European Commission (EC), 1993. Council Directive 93/88/EEC of 12 October 1993 amending Directive 90/679/EEC on the protection of workers from risks related to exposure to biological agents at work (seventh individual Directive within the meaning of Article 16 (1) of Directive 89/391/EEC). Official Journal of the European Union L 268: 71-82.

European Commission (EC), 2003. Regulation (EC) No 1831/2003 of the European Parliament and of the Council of 22 September 2003 on additives for use in animal nutrition. Official Journal of the European Union L 268: 29-43.

European Food Safety Authority (EFSA), 2008. Guidance on the assessment of bacterial susceptibility to antimicrobials of human and veterinary importance. EFSA Journal 6: 732.

European Food Safety Authority (EFSA), 2010. EFSA panel on additives and products or substances used in animal feed (FEEDAP). Scientific opinion on the safety and efficacy of the product Cylactin ${ }^{\oplus}$ (Enterococcus faecium) as a feed additive for chickens for fattening. EFSA Journal 8: 1661.

European Food Safety Authority (EFSA), 2012. EFSA panel on additives and products or substances used in animal feed (FEEDAP). Guidance on the safety assessment of Enterococcus faecium in animal nutrition. EFSA Journal 10: 2682.

European Food Safety Authority (EFSA), 2013a. EFSA panel on additives and products or substances used in animal feed (FEEDAP). Scientific opinion on Cylactin ${ }^{\oplus}$ (Enterococcus faecium) for calves, lambs and kids for rearing and for fattening. EFSA Journal 11: 3097.

European Food Safety Authority (EFSA), 2013b. EFSA panel on additives and products or substances used in animal feed (FEEDAP). Scientific opinion on the safety and efficacy of Cylactin ${ }^{\oplus}$ (Enterococcus faecium) as a feed additive for cats and dogs. EFSA Journal 11: 3098. 
European Food Safety Authority (EFSA), 2014. EFSA panel on additives and products or substances used in animal feed (FEEDAP). Scientific opinion on the safety and efficacy of Cylactin ${ }^{\circledR}$ (Enterococcus faecium NCIMB 10415) as a feed additive for chickens for fattening, chickens reared for laying, minor poultry species for fattening and minor poultry species reared for laying. EFSA Journal 12(11): 3906.

European Food Safety Authority (EFSA), 2015. EFSA panel on additives and products or substances used in animal feed (FEEDAP). Scientific opinion on the safety and efficacy of Cylactin ${ }^{\oplus}$ (Enterococcus faecium NCIMB 10415) as a feed additive for pigs for fattening, piglets and sows. EFSA Journal 13: 4158.

European Food Safety Authority (EFSA), 2017. EFSA panel on biological hazards (BIOHAZ). Scientific opinion on the update of the list of QPS-recommended biological agents intentionally added to food or feed as notified to EFSA. EFSA Journal 15: 4664.

Franz, C.M., Holzapfel, W.H. and Stiles, M.E., 1999. Enterococci at the crossroads of food safety? International Journal of Food Microbiology 47: 1-24.

Franz, C.M., Huch, M. and Holzapfel, W.H., 2009. Probiotische Kapazität von Enterokokken. In: Bischoff, S.C. (ed.) Probiotika, Präbiotika und Synbiotika. Georg Thieme Verlag, Stuttgart, Germany, pp. 118-131.

Franz, C.M., Huch, M., Abriouel, H., Holzapfel, W. and Gálvez, A., 2011. Enterococci as probiotics and their implications in food safety. International Journal of Food Microbiology 151: 125-140.

Franz, C.M., Muscholl-Silberhorn, A.B., Yousif, N.M.K., Vancanneyt, M., Swings, J. and Holzapfel, W.H., 2001. Incidence of virulence factors and antibiotic resistance among Enterococci isolated from food. Applied and Environmental Microbiology 67: 4385-4389.

Franz, C.M., Stiles, M.E., Schleifer, K.H. and Holzapfel, W.H., 2003. Enterococci in foods - a conundrum for food safety. International Journal of Food Microbiology 88: 105-122.

Frigerio, G.A., 1986. Lactic acid producer enterococcus in the prevention of antibiotic-associated diarrhoea and in the treatment of acute diarrhoeal disorders: a double-blind multicentre placebocontrolled clinical trial (Abstract). Digestive Diseases and Sciences 31, Suppl.: 496.

Galimand, M., Schmitt, E., Panvert, M., Desmolaize, B., Douthwaite, S., Mechulam, Y. and Courvalin, P., 2011. Intrinsic resistance to aminoglycosides in Enterococcus faecium is conferred by the $16 \mathrm{~S}$ rRNA $\mathrm{m}^{5}$ C1404-specific methyltransferase EfmM. RNA 17: 251-262.

Gallmann, P. and Puhan, Z., 1982. Die Rohmilchflora im Raclette-Käse aus nicht erhitzter Milch: Entwicklung und Bedeutung während der Fabrikation und Reifung. Schweizer Milchwirtschaftliche Forschung 11: 3-11.

Galloway-Peña, J.R., Rice, L.B. and Murray, B.E., 2011. Analysis of PBP5 of early U.S. isolates of Enterococcus faecium: sequence variation alone does not explain increasing ampicillin resistance over time. Antimicrobial Agents and Chemotherapy 55: 3272-3277.

Ghosh, A., Dowd, S.E. and Zure, L., 2011. Dogs leaving the ICU carry a very large multi-drug resistant enterococcal population with capacity for biofilm formation. PLoS ONE 6: e22451.
Hammer, H.F., 2015. Sinnvoller Einsatz von Antibiotika und die Prävention von Antibiotika-assoziierter Diarrhoe mit probiotischen Arzneimitteln. Journal für Gastroenterologische und Hepatolologische Erkrankungen 13: 20-24.

Hollenbeck, B.L. and Rice, L.B., 2012. Intrinsic and acquired resistance mechanisms in Enterococcus. Virulence 3: 421-433.

Holzapfel, W.H., Haberer, P., Snel, J., Schillinger, U. and Huis in't Veld, J.H.J., 1998. Overview of gut flora and probiotics. International Journal of Food Microbiology 41: 85-101.

Jensen, J.P., Relnibod, G.W. and Vedamuthu, E.R., 1975. Role of enterococci in cheddar cheese: organoleptic considerations. Journal of Milk and Food Technology 38: 142-145.

Kayser, F.H., 2003. Safety aspects of enterococci from the medical point of view. International Journal of Food Microbiology 88: 255-262.

Kern, M., Günzel, D., Aschenbach, J.R., Tedin, K., Bondzio, A. and Lodemann, U., 2017. Altered cytokine expression and barrier properties after in vitro infection of porcine epithelial cells with enterotoxigenic Escherichia coli and probiotic Enterococcus faecium. Mediators of Inflammation 2017: 2748192.

Klein, G., Pack, A., Lower, J. and Reuter, G., 1995. Lebensmittel- und futtermittelrechtliche Fragestellungen bei biotechnisch eingesetzten Probiotika-Stämmen. In: Proceedings of the $36^{\text {th }}$ Conference for food hygiene in Garmisch Partenchirchen. Garmisch Partenchirchen, Germany, pp. 369-375.

Lami, F. and Callegari, C., 1988. SF68 nella sindrome del colon irritabile. In: International symposium on Enterococcus lactic acid bacteria, Wien Austria, 4 March 1988.

Lami, F., Callegari, C. and Barbara, L., 1982. Breath test evaluation of SF68 in IBS patients. In: Symposium on lactic acid bacteria. Clinica Medica, Università di Bologna, Pescara, Italy, 6 February 1982 (Abstract).

Lami, F., Callegari C., Levantesi F., Tatali M., Abbiati R., Barbara L., 1989. Modificazioni indotte dalla somministrazione di Enterococcus faecium in pazienti con sindrome del colon irritabile. In: Simposio Internazionale su Ecologia intestinale: dalla microbiologia alla clinica, Sardegna, Italy, pp. 77-82.

Laulund, S., Wind, A., Derkx, P.M. and Zuliani, S., 2017. Regulatory and safety requirements for food cultures. Microorganisms 5: 28.

Lewenstein, A., Frigerio, G. and Moroni, M., 1979. Biological properties of SF68, a new approach for the treatment of diarrheal diseases. Current Therapeutic Research 26: 967-981.

Loguercio, C., Abbiati, R., Rinaldi, M., Romano, A., Del Vecchio Blanco, C. and Coltorti, M., 1995. Long-term effects of Enterococcus faecium SF68 versus lactulose in in the treatment of patients with cirrhosis and grade 1-2 hepatic encephalopathy. Journal of Hepathology 23: 39-46.

Loguercio, C., Del Vecchio-Blanco, C. and Coltorti, M., 1987. Enterococcus lactic acid bacteria strain SF68 and lactulose in hepatic encephalopathy: a controlled study. Journal of International Medical Research 15: 335-343.

Loizeau, E., 1994. Place de l'Entérocoque SF68 dans la prévention et le traitement des gastro-entérites infectieuses et liées aux antibiotiques. Revue Médicale de la Suisse Romande 114: 651-654. 
Martín, R., Langa, S., Reviriego, C., Jiménez, E., Marín, M.L., Xaus, J., Fernándes, L. and Rodríguez, J.M., 2003. Human milk is a source of lactic acid bacteria for the infant gut. Journal of Pediatrics 143: 754-758.

Mitra, A.K. and Rabbani, G.H., 1990. A double-blind, controlled trial of bioflorin (Streptococcus faecium SF68) in adults with acute diarrhea due to Vibrio cholerae and enterotoxigenic Escherichia coli. Gastroenterology 99: 1149-1152.

Murray, B.E., 1990. The life and times of the Enterococcus. Clinical Microbiology Reviews 3: 46-65.

Rice, L.B., Bellais, S., Carias, L.L., Hutton-Thomas, R., Bonomo, R.A., Caspers, P., Page, M.G. and Gutmann, L., 2004. Impact of specific pbp5 mutations on expression of beta-lactam resistance in Enterococcus faecium. Antimicrobial Agents and Chemotherapy 48: 3028-3032.

Salvioli, G., Salati, R., Bondi, M., Fratalocchi, A., Sala, B.M. and Gibertini, A., 1982. Bile acid transformation by the intestinal flora and cholesterol saturation in bile. Digestion 23: 80-88.

Sanders, M.E., Akkermans, L.M.A., Haller, D., Hammerman, C., Heimbach, J.T., Hörmannsperger, G. and Huys, G., 2010. Safety assessment of probiotics for human use. Gut Microbes 1: 164-185.

Schiraldi, O., Di Bari, C. and Trotta, F., 1982. Le traitement par Streptococcus faecium des porteurs asymptomatiques de Salmonelles. Médecine et Hygiène 40: 445-446.

Sellmaier, F., 2007. Vergleich der phänotypischen Eigenschaften epidemischer und sporadischer Enterococcus faecium Stämme. Dissertation zur Erlangung des Medizinischen Doktorgrades der Medizinischen Fakultät der Albert-Ludwigs-Universität Freiburg. Available at: https://tinyurl.com/y8lb9vh6.

Shanker, E. and Federle, M.J., 2017.Quorum sensing regulation of competence and bacteriocins in Streptococcus pneumoniae and mutans. Genes 8: 15.

Singh, K.V., Coque, T., Weinstock, G.M. and Murray, B., 1998. In vivo testing of an Enterococcus faecalis efaA mutant and use of efaA homologs for species identification. FEMS Immunology and Medical Microbiology 21: 323-331.

Singh, K.V., Malathum, K. and Murray, B., 2001. Disruption of an Enterococcus faecium species-specific gene, a homologue of acquired macrolide resistance genes of Staphylococci is associated with an increase in macrolide susceptibility. Antimicrobial Agents and Chemotherapy 45: 263-266.

Sparre-Linde, L. and Lindwall L., 1986. The effect of ventrux acido (lactic acid-forming bacteria) on tourist diarrhoea - a double blind study. Swedish Journal of Biological Medicine 3/86.
Švec, P. and Franz, C.M.A.P., 2014. Genus Enterococcus. In: Holzapfel, W.H. and Wood, B.J.B. (eds.) Lactic acid bacteria - biodiversity and taxonomy. John Wiley and Sons Ltd., Chichester, UK, pp. 175-211.

Underdahl, N.R., Torres-Medina, A. and Doster, A.R., 1982. Effect of Streptococcus faecium C-68 in control of Escherichia coli-induced diarrhea in gnotobiotic pigs. American Journal of Veterinary Research 43: 2227-2232.

Vancanneyt, M., Lombardi, A., Andrighetto, C., Knijff, E., Torriani, S., Björkroth, K.J., Franz, C.M.A.P., Foulquié Moreno, M.R., Revets, H., De Vuyst, L., Swings, J., Kersters, K., Dellaglio, F. and Holzapfel, W.H., 2002. Intraspecies genomic groups in Enterococcus faecium and their correlation with origin and pathogenicity. Applied and Environmental Microbiology 68: 1381-1391.

Vankerckhoven, V.G.H., Huys, G., Vancanneyt, M., Vael. C., Klare, I., Romond, M., Entenza, J., Moreillon, P., Wind, R.D., Knol, J., Wiertz, E., Pot, B., Vaughan, E.E., Kahlmeter, G. and Goossens, H., 2008a. Biosafety assessment of probiotics used for human consumption: recommendations from the EU-PROSAFE project. Trends in Food Science and Technology 19: 102-114.

Vankerckhoven, V.G.H., Lammens, C., Chapelle, S., Wijdooghe, M., Ieven, M. and Goossens, H., 2005. Colonization potential of Enterococcus faecium SF68 following its administration to healthy volunteers. In: Proceedings of the European Conference on Probiotics and their Applications (EUPROBIO). October 6-8, 2005. Krakow, Poland, p. 34.

Vankerckhoven, V.G.H., Vancanneyt, M., Snauwaert, C., Swings, J., Klare, I., Witte, W., Van Autgaerden, T., Chapelle, S., Lammens, C. and Goossens, H., 2008b. Genotypic diversity, antimicrobial resistance, and virulence factors of human isolates and probiotic cultures constituting two intraspecific groups of Enterococcus faecium isolates. Applied and Environmental Microbiology 74: 4247-4255.

Werner, G., Fleige, C., Geringer, U., Van Schaik, W., Klare, I. and Witte, W., 2011. IS element IS16 as a molecular screening tool to identify hospital-associated strains of Enterococcus faecium. BCM Infectious Diseases 11: 80.

Wopereis, H., Oozer, R., Knipping, K., Belzer, C. and Knol, J., 2014. The first thousand days - intestinal microbiology of early life: establishing a symbiosis. Pediatric Allergy and Immunology 25: 428-438.

Wunderlich, P.F., Braun, L., Fumagalli, I., D’Apuzzo, V., Heim F., Karly, M., Lodi, R., Politta, G., Vonbank, F. and Zeltner, L., 1989. Doubleblind report on the efficacy of lactic acid-producing Enterococcus SF68 in the prevention of antibiotic-associated diarrhoea and in the treatment of acute diarrhoea. Journal of International Medical Research 17: 333-338. 